\title{
VENLAFAXINE INDUCED-MYOCLONUS IN A PATIENT WITH MIXED DEMENTIA
}

\author{
Livia Almeida Dutra, José Luiz Pedroso, Evandro Penteado Villar Felix, Orlando Graziani Povoas Barsottini
}

Myoclonus is a clinical sign defined as sudden, brief, shock like, involuntary movements caused by muscular contractions or inhibitions'. Certain commonly prescribed drugs cause movements disorders as myoclonic jerks and polymyoclonus in the absence of other signs of toxicity². Venlafaxine is a serotonin-norepinephrine reuptake inhibitor used for the treatment of depression, post traumatic stress disorder, obsessive compulsive disorders, chronic pain and menopausal symptoms s.4. $^{3,4}$.

We report a case of myoclonus induced by venlafaxine in a patient with mixed dementia.

\section{CASE}

A seventy-five-year-old female presented to neurologic consultation at emergency department complaining of tremors and abnormal movements that started 4 days before the admission. It started in the four limbs and face at the same time, and according to her daughter, they were shock like, abrupt and nonrhythmical. The patient denied any similar events before. The movements could not be suppressed. Her medical history showed 3 minor strokes, but no sequelae, hypertension and a mixed dementia which was diagnosed 3 years before. She needed some help for common activities such as bathing and taking medications due memory problems. For the treatment of dementia she was receiving galantamine $8 \mathrm{mg}$ twice a day and risperidone $1 \mathrm{mg}$ per day for almost 10 months. She also received enalapril $20 \mathrm{mg}$ and aspirin $100 \mathrm{mg}$ per day. Twelve days before the admission, her physician prescribed venlafaxine $75 \mathrm{mg}$ per day for depression. She denied other medications, fever or cough.

Physical examination showed an arterial pressure of 130 per $80 \mathrm{mmHg}$ and regular cardiac rhythm. She was alert and cooperative. There was no face rubor. Myoclonus was present in inferior limbs, superior limbs and face. There were no signs of parkinsonism. Motor strength, sensory functions and language were preserved but she presented snout and palmomentonian reflexes.

Her Mini Mental was 13. Blood count, blood chemistry including glucose, sodium, potassium and calcium levels was normal. Urinalysis excluded infection. We also performed a CT scan which did not show evidence of stroke.
We decided to stop venlafaxine and after 3 days the myoclonus ceased.

\section{DISCUSSION}

It is well described in the current literature the association of myoclonus with anticonvulsivants, antidepressants, antipsychotic, cephalosporin and carbapenem antibiotics $^{2,4,5}$. Although our patient was receiving risperidone, we believe that myoclonus was induced by venlafaxine, once there was a complete remission after discontinuation of the drug. Venlafaxine was associated with other movements disorders as blepharoespams ${ }^{2}$ and myoclonus in the setting of serotonin syndrome, which is a potentially fatal complication of the combined use of agents that enhance serotonin activity ${ }^{3}$, but we couldn 1 t find any report of myoclonus and venlafaxine without serotonin syndrome.

Degenerative diseases might present with myoclonus, but the myoclonus seen in some of these disorders has been primarily limited to small-amplitude jerks of the distal limbs (predominantly fingers), termed minipolymyoclonus. Our patient presented a more generalized and prominent myoclonus, that should raise the possibility of drug-induced myoclonus ${ }^{6}$.

We believe that myoclonus was induced by the serotonergic effects of venlafaxine. The relation between serotonin and myoclonus was first documented by Lhermitte ${ }^{7}$. There are several reports of myoclonus and other movements disorders induced by selective inhibitors of serotonin ${ }^{2-4,8-10}$. In one of them, Lauterbach reported myoclonus induced by fluoxetine in a patient with Pick disease ${ }^{8}$ and postulated that might be an underlying hypersensitivity of $5 \mathrm{HT}_{1 \mathrm{~A}}$ receptors in Pick's disease. Recently upregulation of $5 \mathrm{HT}_{1 \mathrm{~A}}$ receptors in hippocampus in mild cognitive impairment was described, as well as reduction in the number of receptors $5 \mathrm{HT}_{1 \mathrm{~A}}$ in the hippocampus of $\mathrm{pa}-$ tients with Alzheimer disease ${ }^{9,11,12}$. Thus, it is possible that a dysfunction in the serotonin pathway exists in degenerative diseases, which predisposes to serotonin inhibitors-

\section{MIOCLONIAS INDUZIDAS POR VENLAFAXINA EM UMA PACIENTE COM DEMÊNCIA MISTA}

Department of Neurology, Federal University of São Paulo, São Paulo SP, Brazil.

Received 29 July 2008, received in final form 25 September 2008. Accepted 7 October 2008.

Dra. Lívia Almeida Dutra - Rua Borges Lagoa 512 / 61C - 04038-000 São Paulo SP - Brasil. E-mail: liviaadutra@hotmail.com 
induced movement disorders. This is in accordance with a review of movement disorders and serotonin reuptake inhibitors conducted by Gerber and Lynd, who concluded that patients at higher risk may be those with preexisting neurologic disorders and the elderly. Also, the combined use of neuroleptic and serotonin reuptake inhibitors increases the susceptibility of movement disorders ${ }^{10}$.

We conclude that older patients, especially those presenting degenerative diseases are at risk for movement disorders when serotonin reuptake inhibitors are prescribed. One should carefully evaluate patients with degenerative disease in use of venlafaxine and other serotonin reuptake inhibitors.

\section{REFERENCES}

1. Munhoz RP. Serotonin syndrome induced by a combination of bupropion and SSRIs. Clin Neuropharmacol 2004;27:219-222.

2. Yu Lee, Wei-Chiang Yeh, Mian-Yoon Chong, Pao-Yen Lin. Venlafaxine and tardive blepharospasm: a case report. Progr Neur Psychopharmacol Biol Psychiatry 2007;31:1139-1140.
3. Caviness JN, Brown P. Myoclonus: current concepts and recent advances. Lancet Neurol 2004;3:598-607.

4. Ghika-Schmid F, Ghika J, Vuadens P, Bogousslavsky J, Regli F, Despland PA. Acute reversible myoclonic encephalopathy associated with fluoxetine therapy. Mov Disord 1997;12:622-623.

5. Frucht S, Eidelberg D. Imipenem-induced myoclonus. Mov Disord 1997;12:621-622.

6. McKeon A, Pittock SJ, Glass GA, et al. Whole-body tremulousness. Arch Neurol 2007;64:1318-1322.

7. Lhermitte F, Peterfalvi M, Marteau R, Gazengel J, Serdaru M. Pharmacological analysis of a case of postanoxic intention and action myoclonus. Rev Neurol (Paris) 1971;124:21-31.

8. Lauterbach EC. Reversible intermittent rhythmic myoclonus with fluoxetine in presumed Pick's disease. Mov Disord 1994;3:343-346.

9. Mowla A, Mosavinasab M, Haghshenas H, Haghighi AB. Does serotonin augmentation have any effect on cognition and activities of daily living in Alzheimer's dementia? A double- blind, placebo-controlled clinical trial. J Clin Psychopharmacol 2007;27:484-487.

10. Gerber PE, Lynd LD. Selective serotonin-reuptake inhibitor-induced movement disorders. Ann Pharmacother 1998;32:692-698.

11. Truchot L, Costes SN, Zimmer L, et al. Up-regulation of hippocampal serotonin metabolism in mild cognitive impairment Neurology 2007; 69:1012-1017.

12. Lai MK, Tsang SW, Francis PT, et al. Postmortem serotoninergic correlates of cognitive decline in Alzheimer's disease. Neuroreport 2002; 13:1175-1178. 